\title{
Allelic variation at Glu-1 loci and its association with grain quality of wheat grown in an irrigated hot environment
}

\author{
Izzat S. A. Tahir ${ }^{1,2}$, Osman S. Abdalla ${ }^{2}$, Nakata Noboru ${ }^{3}$, Hala M. M. Elamein ${ }^{1 \star}$, Abdelbagi M. \\ Ali $^{1}$ and Fouad J. El-Haramein ${ }^{2}$ \\ ${ }^{1}$ Agricultural Research Corporation, P.O Box 126, Wad Medani, Sudan. \\ ${ }^{2}$ International Center for Agricultural Research in the Dry Areas (ICARDA), P.O Box 5466, Aleppo, Syria. \\ ${ }^{3}$ Faculty of Agriculture, Tottori University, Koyama 4-101, Tottori 680-8553, Japan.
}

Accepted 22 June, 2011

The high molecular weight glutenin subunits (HMW-GS) are important determinants of wheat flour quality. The HMW-GS patterns of the major released wheat cultivars in Sudan, in addition to some advanced lines, were analyzed using SDS-PAGE. The associations of the HMW-GS quality scores (Glu-1 QS) with the flour protein content (PC), insoluble protein content (IPC), sodium dodecyl sulfate sedimentation (SDSS) test and some mixograph attributes measured using flours of 16 wheat genotypes grown in a hot irrigated environment were also studied. A total of 15 different HMW-glutenin individual subunits were detected. Particularly, three subunits (null, 1 and $2^{\star}$ ) were identified at Glu-A1, eight subunits at Glu-B1 that fall into six subunit combinations $\left(7,7+8,7+9,7+15_{1}, 13+16\right.$ and 17+18) and four subunits at the Glu-D1 locus that fall into two combinations $(2+12$ and $5+10)$. Some cultivars were heterogeneous in their HMW-GS composition such as El Nielain, Sasaraib and Nesser. The Glu-1 QS significantly correlated with PC, IPC, SDSS and mixograph curve width 2 min past peak. However, no significant associations were found between Glu-1 QS and other mixograph parameters such as mixograph peak height, mixograph peak time and mixograph descending slope 2 min past peak. The results show that subunit combination of $5+10$ that has major effect on dough strength was lacking in all cultivars released before 1990, while the frequency of this subunit combination was high in the tested advanced lines. The results obtained in this study could be useful in breeding programs to improve the end-use quality in bread wheat. HMW-GS patterns could also serve as complementary markers in cultivar identification, purification and improvement.

Key works: Wheat, high molecular weight glutenin subunits, SDS-PAGE, allelic variation, quality scores, hot environment.

\section{INTRODUCTION}

Wheat (Triticum aestivum L.) is the most important food crop worldwide because of its wide adaptation to diverse environments and the uniqueness of possessing a viscoelastic protein complex called gluten. Wheat quality

*Corresponding author. E-mail: mustha_3@yahoo.com.

Abbreviations: HMW-GS, High molecular weight glutenin subunits; PC, protein content; IPC, insoluble protein content; SDSS, sodium dodecyl sulfate sedimentation. is essentially determined by the composition and the amount of the two major components of gluten which are glutenin and gliadin proteins. The unique dough elasticity is mainly influenced by polymeric glutenins, while monomeric gliadins define viscous behavior of dough (Payne and Lawrence, 1983; Payne et al., 1987; Shewry and Halford, 2002).

The high molecular weight-glutenin subunits (HMWGS) and low molecular weight glutenin subunits (LMWGS) explain the variation in all quality parameters better than gliadin components (Payne and Lawrence, 1983; Wieser and Kieffer, 2001). The HMW-GS are encoded by 
polymorphic genes at Glu-1 loci (Glu-A1, Glu-B1 and GluD1) present on the long arms of the group 1 chromosomes (Payne and Lawrence, 1983). The HMWGS play an important role in determining genotypic variation in bread making quality of wheat (Payne and Lawrence, 1983; Payne et al., 1987; Randall et al., 1992; Branlard et al., 2001; Ali et al., 2010) despite the fact that they constitute only $10 \%$ of storage proteins of the wheat endosperm. In particular, HMW-GS $5+10$ and 2+12 at the Glu-D1 locus have a major effect on dough strength (Payne and Lawrence, 1983; Payne et al., 1987). The relationship between gluten proteins composition and the quality parameters has been considered by wheat breeders around the world to develop new wheat varieties with good end-use quality. Payne et al. (1987) proposed the use of the so called, 'Glu-1 quality score' for the prediction of baking quality of wheat varieties based on worldwide observations relating to correlations between HMW-GS patterns and wheat quality. The glutenin composition of bread wheat adapted to the heat stress environment of Sudan has been rarely studied. Furthermore, the relationship between the HMW-GS composition and different quality attributes for wheat grown under hot, irrigated environments similar to that which prevail in Sudan has not been investigated. The objectives of this study were to determine the HMW-GS composition of a historical set of bread wheat varieties released in Sudan and to investigate the association of HMW-GS composition with different quality parameters of some wheat genotypes grown under a hot irrigated environment.

\section{MATERIALS AND METHODS}

Twenty five genetically diverse bread wheat genotypes selected to cover more than five decades of genetic improvement and some of the elite lines in the pipeline of breeding program in Sudan were used in this study. In addition, Chinese Spring was included as a reference genotype (Table 1 ).

The high molecular weight gluten subunits (HMW-GS) composition of each genotype was determined by sodium dodecyl sulfate polyacrylamide gel electrophoresis (SDS-PAGE) system using $10 \%(\mathrm{w} / \mathrm{v})$ acrylamide gels following modified procedures of Laemmli (1970). Each mg of flour sample was suspended in 0.025 $\mathrm{ml}$ of a sample buffer containing $5 \%(\mathrm{v} / \mathrm{v}) 2$ 2-mercaptoethanol, $2 \%$ $(\mathrm{w} / \mathrm{v})$ SDS, $0.0625 \mathrm{M}$ Tris- $\mathrm{HCl}(\mathrm{pH} \mathrm{6.8)}, 10 \%$ (v/v) glycerol and $0.001 \%(\mathrm{w} / \mathrm{v})$ pyronin $\mathrm{Y}$. Samples were vortexed every $15 \mathrm{~min}$ for 5 times and then incubated in a water bath at $95^{\circ} \mathrm{C}$ for $5 \mathrm{~min}$. They were allowed to cool and then stored at $-20^{\circ} \mathrm{C}$ until used. Ten micro litres of each sample was loaded onto the gel and the electrophoresis was run at $10 \mathrm{~mA}$ until the dye reached the bottom of the gel. Gels were stained with $0.025 \%$ Coomassie Brilliant Blue R-250 and destained with a destaining solution containing $40 \%$ methanol and $7 \%$ acetic acid. For better resolution of the subunits 1,2 and $2^{*}$, a further SDS-PAGE analysis was performed according to Huang and Khan (1998) with few modifications. A gel concentration of $12.5 \%$ was used and run at $9 \mathrm{~mA}$. The nomenclature system of Payne and Lawrence (1983) was used for the HMW-GS identification.

To study the association of the detected HMW-GS with different quality attributes, an experiment was carried out at the Gezira
Research Farm (GRF), Agricultural Research Corporation (ARC), Wad Medani, Sudan in 2002/2003. The clay plain of the central Sudan where GRF is located $\left(14^{\circ} 24^{\prime} \mathrm{N}, 33^{\circ} 29^{\prime} \mathrm{E}, 407 \mathrm{~m}\right.$ asl) is characterized by cracking heavy clay vertisols, with very low water permeability, $\mathrm{pH}$ of about 8.5 , poor in organic matter, deficient in available nitrogen and phosphorus. The experiment was planted using 18 of the earlier-mentioned genotypes under two sowing dates: optimum and late (3rd week of November and 2nd week of December, respectively). The late sowing was practiced to expose the crop to very high temperatures during the grain filling period, although, even optimally sown wheat in the clay plain of central Sudan is subjected to sporadic heat stress during most of the growth stages. A randomized complete block design with three replications was used. For more details on experimental site, climatic conditions and cultural practices refer to Tahir et al. (2006).

Wheat grains were cleaned and milled to whole meal on a UDY Cyclone Sample Mill (Udy Corp., Fort Collins, CO, USA) with a 1.00 $\mathrm{mm}$ sieve, and to flour on a Brabender Quadrumat Jr. Laboratory Mill (Brabender Inc., Germany) following method 26-50 (American Association of Cereal Chemists, 2000). The milled samples were stored in airtight containers until analyses were carried out. Flour protein content (PC), and insoluble protein content (IPC) were measured photometrically using the indophenol method (Tahir et al., 2006). Mixograph peak height (MPH), mixograph peak time (MPT), mixograph descending slope 2 min past peak (MDS) and mixograph curve width 2 min past peak (MCW) were carried out following method 54-40A (American Association of Cereal Chemists, 2000) as described in Tahir et al. (2006).

HMW-GS quality score (Glu-1 QS) proposed by Payne et al. (1987) was used. Simple correlation coefficients of Glu-1 QS with various quality attributes were calculated. Genotypes with heterogeneous HMW-GS composition were not used in the computation of the correlation coefficients because of the differences in the quality scores among different biotypes. The correlation coefficients were calculated using genotype means for each sowing date separately ( $n=16$ for each).

\section{RESULTS AND DISCUSSION}

\section{HMW-GS composition}

HMW-GS compositions of wheat genotypes analyzed in this study are shown in Table 1 and figure 1 . A total of 15 different HMW-glutenin individual subunits were detected. In particular, three subunits (null, 1 and $2^{*}$ ) were identified at Glu-A1, eight subunits at Glu-B1 that fall into six subunit combinations $\left(7,7+8,7+9,7+15_{1}, 13+16\right.$ and $17+18)$ and four subunits at the Glu-D1 locus that fall into two subunit combinations $(2+12$ and $5+10)$. Different patterns of HMW-glutenin subunits were detected within genotypes El Nielain, Sasaraib and Nesser.

Individual seeds analyzed from previously selected biotypes of the cultivar El Nielain showed the presence of subunit 1 in two biotypes, while no Glu $A 1$ allele was found in the three other biotypes. The subunit composition of the five biotypes was similar at Glu B1 $\left(7+15_{1}\right)$. Four biotypes possessed the subunit combination of $5+10$ at Glu $D 1$, while the fifth showed the subunit combination of $2+12$. Two biotypes of El Nielain had similar HMW-GS composition. However, it was noticed that they have different band patterns of low molecular weight subunit (data not shown). 
Table 1. HMW-G subunits and corresponding quality scores of historical bread wheat in Sudan.

\begin{tabular}{|c|c|c|c|c|c|c|c|c|}
\hline \multirow{2}{*}{ Genotype } & \multirow{2}{*}{$\begin{array}{l}\text { Year of } \\
\text { release }\end{array}$} & \multicolumn{3}{|c|}{ HMW-GS at Glu-1 } & \multicolumn{3}{|c|}{ Quality score } & \multirow{2}{*}{ Total } \\
\hline & & Glu-A1 & Glu-B1 & Glu-D1 & Glu-A1 & Glu-B1 & Glu-D1 & \\
\hline Beladi & 1960 & Null & $7+8$ & $2+12$ & 1 & 3 & 2 & 6 \\
\hline Giza 144 & Intro. & $2^{*}$ & $7+8$ & $2+12$ & 3 & 3 & 2 & 8 \\
\hline Giza 148 & Intro. & $2^{*}$ & $7+8$ & $2+12$ & 3 & 3 & 2 & 8 \\
\hline Falchetto & 1968 & 1 & $7+8$ & $2+12$ & 3 & 3 & 2 & 8 \\
\hline Giza 155 & 1971 & 1 & $13+16$ & $2+12$ & 3 & 3 & 2 & 8 \\
\hline Mexicani & 1972 & Null & $7+8$ & $2+12$ & 1 & 3 & 2 & 6 \\
\hline Condor & 1978 & Null & $7+8$ & $2+12$ & 1 & 3 & 2 & 6 \\
\hline Debeira & 1982 & Null & $7+8$ & $2+12$ & 1 & 3 & 2 & 6 \\
\hline Wadi EI Neil & 1987 & 1 & $13+16$ & $2+12$ & 3 & 3 & 2 & 8 \\
\hline El Nielain & 1990 & & & & & & & \\
\hline El Nielain-1 & & Null & $7+15_{1}$ & $5+10$ & 1 & 2 & 4 & 7 \\
\hline El Nielain-2 & & 1 & $7+15_{1}$ & $5+10$ & 3 & 2 & 4 & 9 \\
\hline El Nielain-3 & & 1 & $7+15_{1}$ & $5+10$ & 3 & 2 & 4 & 9 \\
\hline El Nielain-4 & & Null & $7+15_{1}$ & $2+12$ & 1 & 2 & 2 & 5 \\
\hline El Nielain-5 & & Null & $7+15_{1}$ & $5+10$ & 1 & 2 & 4 & 7 \\
\hline Sasaraib & 1992 & & & & & & & \\
\hline Sasaraib-1 & & 1 & $7+9$ & $5+10$ & 3 & 2 & 4 & 9 \\
\hline Sasaraib-2 & & 1 & $13+16$ & $2+12$ & 3 & 3 & 2 & 8 \\
\hline Nesser & 1996 & & & & & & & \\
\hline Nesser-1 & & Null & $7+8$ & $2+12$ & 1 & 3 & 2 & 6 \\
\hline Nesser-2 & & Null & $17+18$ & $2+12$ & 1 & 3 & 2 & 6 \\
\hline Argine & 1998 & Null & $7+8$ & $2+12$ & 1 & 3 & 2 & 6 \\
\hline Imam & 2000 & $2^{*}$ & 7 & $5+10$ & 3 & 1 & 4 & 8 \\
\hline Tagana & 2004 & 1 & $7+8$ & $2+12$ & 3 & 3 & 2 & 8 \\
\hline Khalifa & 2004 & 1 & $7+9$ & $5+10$ & 3 & 2 & 4 & 9 \\
\hline Bohaine & 2006 & Null & $7+8$ & $2+12$ & 1 & 3 & 2 & 6 \\
\hline Gezira-11 & 2006 & 1 & $7+9$ & $2+12$ & 3 & 2 & 2 & 7 \\
\hline Nebta & 2007 & $2^{*}$ & $7+9$ & $5+10$ & 3 & 2 & 4 & 9 \\
\hline VYT 97/98 \# 3 & $-^{a}$ & Null & $7+8$ & $2+12$ & 1 & 3 & 2 & 6 \\
\hline VYT 97/98 \# 8 & - & $2^{*}$ & $17+18$ & $5+10$ & 3 & 3 & 4 & 10 \\
\hline HTWYT 99/00 \# 42 & - & Null & $7+8$ & $2+12$ & 1 & 3 & 2 & 6 \\
\hline $\mathrm{DH}-12$ & - & 1 & $7+9$ & $2+12$ & 3 & 2 & 2 & 7 \\
\hline Pastor & - & 1 & $17+18$ & $5+10$ & 3 & 3 & 4 & 10 \\
\hline Pfau/Weaver & - & 1 & $7+9$ & $5+10$ & 3 & 2 & 4 & 9 \\
\hline Chinese Spring & $-b$ & Null & $7+8$ & $2+12$ & 1 & 3 & 2 & 6 \\
\hline
\end{tabular}

The genotypes included in quality assessment experiment are given in bold. Intro. = Introduced from Egypt; $-^{\mathrm{a}}=$ elite line; $-^{\mathrm{b}}=$ reference genotype.

These two biotypes could be used for further investigation on the effect of that particular subunit on the quality. The pattern in the two previously selected biotypes of Sasaraib was different at Glu B1 and Glu D1. One of them showed subunit combination of $1,7+9$ and $5+10$, while the other showed subunits $1,13+16$ and $2+12$. Two different subunit combinations at Glu-B1 $(7+8$ and 17+18) were detected in Nesser.

Among the 15 allelic variants detected, subunit null at Glu-A1 was the most frequent as represented in $44 \%$ of released cultivars (including different biotypes within a cultivar). The remaining cultivars showed subunits 1 and $2^{*}$ with frequencies of 40 and $16 \%$, respectively. The most frequent subunits at the Glu-B1 was $7+8(44 \%)$ followed by $7+9(19 \%)$ and $7+15_{1}(16 \%)$. The remaining cultivars showed subunits $13+16,17+18$, and 7 with frequencies of 9,9 and $3 \%$, respectively. At the Glu-D1 locus, only two pairs of subunits $2+12$ and $5+10$ were present at frequencies of 66 and $34 \%$, respectively. The results showed that all cultivars released before 1990 were lacking the subunit combination of $5+10$. On the other hand, the frequency of this subunit combination 


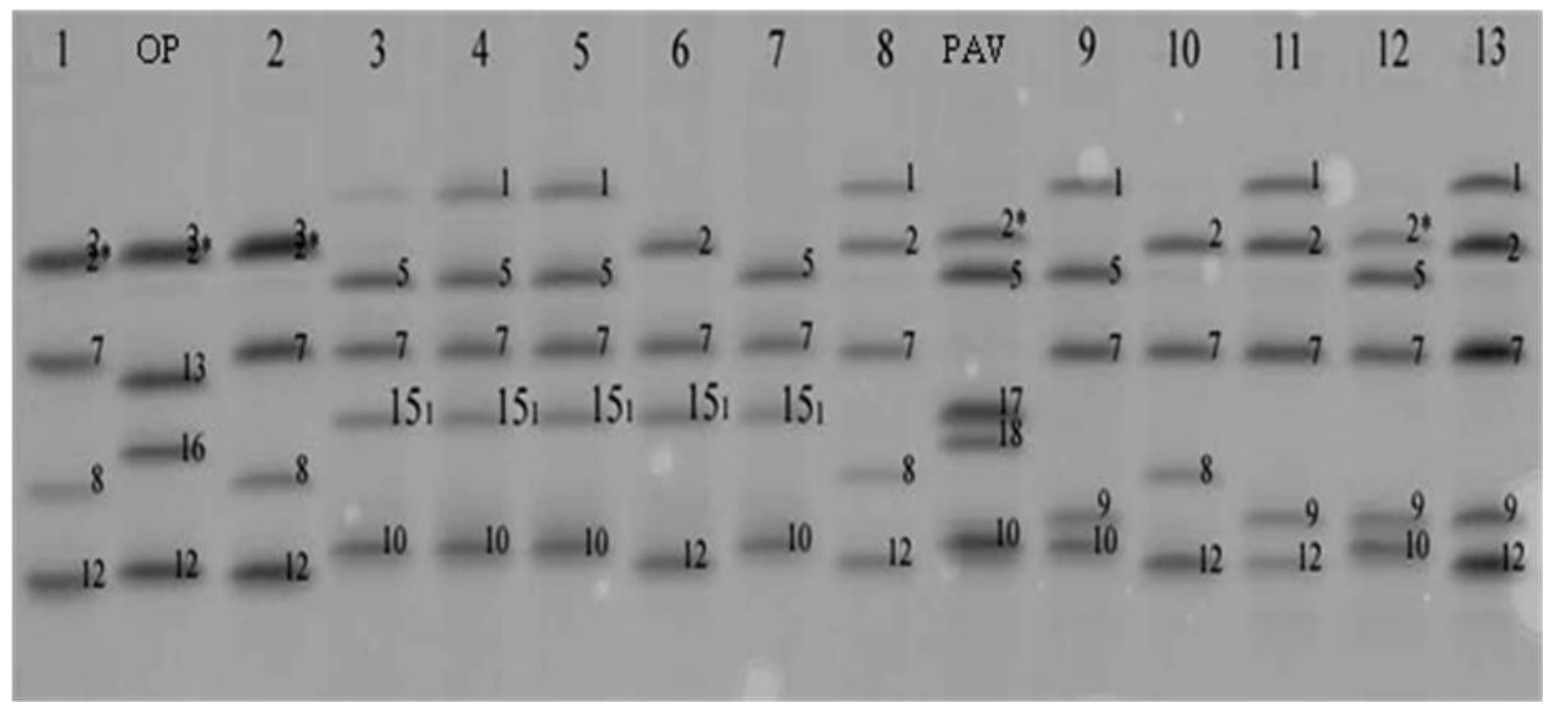

Figure 1. SDS-PAGE patterns of the HMW-GS extracted from seeds of some bread wheat genotypes used in this study: (1) Giza 144; (OP) Opata; (2) Giza 148; (3) El Nielain-1; (4) El Nielain-2; (5) El Nielain-3; (6) El Nielain-4; (7) El Nielain-5; (8) Tagana; (PAV) Pavon; (9) Khalifa; (10) Bohaine; (11) Gezira-11; (12) Nebta and (13) DH-12.

was high in the advanced lines tested. SDS-PAGE patterns of the HMW-GS extracted from seeds of some bread wheat genotypes used in this study are shown in Figure 1. With the challenges that the wheat breeding program was facing for successful introduction and expansion of wheat production into non-traditional, heatstressed environments of Sudan, little consideration was given to end-use quality of wheat during that time (Elahmadi, 1996; Tahir et al., 2009).

\section{Glu-1 quality scores}

The Glu-1 quality scores of genotypes included in this study ranged from 5 in one of El Nielain biotypes to 10 in two elite lines of the breeding program (Table 1). No cultivar released prior 1990 had score higher than 8 . The biotypes of El Nielain varied in their Glu-1 quality scores from 5 to 9 , while the two biotypes of Nesser showed similar score of 6 .

\section{Association of Glu-1 QS with grain quality attributes under a hot environment}

The Glu-1 quality score (Glu-1 QS) of the bread wheat genotypes used in this study and grown under the heatstressed condition of GRF significantly correlated with the total protein content at optimum sowing $(P<0.05)$ and late sowing $(P<0.01)$ dates (Table 2$)$.

Similar relationships were found between Glu-1 QS and insoluble protein content under both sowing dates (Table 2).The strongest association of Glu-1 QS with different quality parameters measured was with SDS sedimen- tation volumes. Highly significant correlation coefficients were found between Glu-1 QS and SDS sedimentation volume under optimum and late sowing conditions $(P<$ 0.001) (Table 2). This strong association of SDS sedimentation with Glu-1 QS is in agreement with the results of previous studies that led to proposing SDS sedimentation as a primary screen to test the desired subunits in breeding lines (Lorenzo et al., 1987).

Except for mixograph curve width 2 min past peak of the optimum sowing date $(r=0.576, P=0.02)$, no significant correlation coefficients were recorded between Glu-1 QS and all other mixograph parameters measured in this study including mixograph peak height, mixograph peak time and mixograph descending slope 2 min past peak (Table 2).

The association of Glu-1 QS with some quality parameters measured using grains harvested from wheat grown under high temperature condition is in agreement with those reported under different growing conditions (Payne et al., 1987; Zheng et al., 2010). However, the absence of significant associations with most of the mixograph parameters could be because of alteration in grain quality induced by high temperatures during grain filling (Tahir et al., 2006). It has been noticed that the associations of Glu-1 QS with the mixograph parameters were always weaker for the late sowing as compared to the optimum sowing, except for mixograph peak time. The high temperatures that prevail during the grain filling period of late sowing have been found to alter many grain quality attributes, especially the mixograph parameters (Tahir et al., 2006).

The lack of associations of all quality parameters with Glu-1 QS suggested that the latter is not an exclusive indicator of various quality attributes of grain grown under 
Table 2. Correlation coefficients ( $r$ ) of Glu-1 quality score with different quality attributes of 16 bread wheat genotypes grown in two sowing dates (optimum and late) at Gezira Research Farm, Wad Medani, Sudan.

\begin{tabular}{lll}
\hline Quality attribute & Glu-1 quality score & P-value \\
\hline 1- Protein content (\%) & & \\
Optimum sowing & 0.501 & 0.047 \\
Late sowing & 0.651 & 0.005 \\
& & \\
2- Insoluble protein content (\%) & 0.631 & 0.007 \\
Optimum sowing & 0.672 & 0.003 \\
Late sowing & & \\
3- SDS Sedimentation volume (ml) & 0.803 & 0.000 \\
Optimum sowing & 0.765 & 0.000 \\
Late sowing & & \\
& & \\
4- Mixograph peak height (\%) & 0.474 & 0.064 \\
Optimum sowing & 0.037 & \\
Late sowing & & 0.895 \\
& & 0.202 \\
5- Mixograph peak time (min) & -0.340 & \\
Optimum sowing & -0.434 & \\
Late sowing & & 0.208 \\
& & 0.485 \\
6- Mixograph descending slope 2 min past peak (\%) & & \\
Optimum sowing & 0.336 & 0.020 \\
Late sowing & 0.191 & 0.710 \\
\hline & & \\
7- Mixograph curve width 2 min past peak (\%) & 0.567 & \\
Optimum sowing & & \\
Late sowing & & \\
\hline
\end{tabular}

high temperature conditions. Low molecular weight glutenin subunits and gliadin proteins and their interaction with the HMW-GS alleles in the genotype background are reported to significantly affect different grain quality parameters (Branlard et al., 2001; Flaete and Uhlen, 2003). Further detailed studies on the involvement of different glutenin and glaidin components and their ratios in determining the grain quality under heat stress environment of Sudan is needed. Moreover, further dough rheology tests such as farinograph, extensograph and alveograph could be done to determine the dough strength and extensibility of wheat grown under these heat stress areas.

The results obtained in this study are useful in breeding programs to improve the end-use quality in bread wheat. HMW-GS could serve as complementary markers in cultivar identification and purity improvement. However, determination of quality characteristics of cultivars heterogeneous for HMW-GS patterns might not be accurate especially when HMW-GS is used during early generations of the breeding programs. The deteriorating effects of high temperatures during grain filling period on different quality attributes could have resulted in the absence of association of HMW-GS composition with different mixograph quality parameters.

\section{REFERENCES}

Ali M, Saddiqui MF, Ullah I, Bakht J (2010). Analysis of HMWGS of historical set of Pakistani bread wheat varieties using SDS-PAGE. Afr. J. Biotechnol. (9): 4286-4289.

American Association of Cereal Chemists (2000). Approved Methods of the AACC, $10^{\text {th }}$ edn. Method, 54-40A. AACC. St Paul, MN. 54-40A.

Branlard G, Dardevet M, Saccomano R, Lagoutte F, Gourdon J (2001). Genetic diversity of wheat storage proteins and bread wheat quality. Euphytica, (119): 59-67.

Elahmadi AB (1996). Review of wheat breeding in the Sudan. In: Ageeb $\mathrm{OA}$, Elahmadi $\mathrm{AB}$, Solh MB, Saxena MC (ed). Wheat production and improvement in the Sudan. Proc. Natl. Res. Rev.iew Workshop, 2730 August 1995, Wad Medani, Sudan. ICARDA/ Agric.ultural Res.earch Corpora.tion. ICARDA, Aleppo, Syria: pp. 33-53.

Flaete NES, Uhlen AK (2003). Association between allelic variation at the combined Gli-1, Glu-3 loci and protein quality in common wheat (Triticum aestivum L.). J. Cereal Sci. (37): 129-137.

Huang DY, Khan K (1998). A modified SDS-PAGE procedure to separate high molecular weight glutenin subunits 2 and $2^{*}$. J. 
Cereal Sci. (27): 237-239.

Laemmli UK (1970). Cleavage of structural proteins during the assembly of the head of the bacteriophage T4. Nature (London) (227): 680-685.

Lorenzo A, Kronstad WE, Vieira GE (1987). Relationship between high molecular weight glutenin subunits and loaf volume in wheat as measured by sodium dodecyl sulphate sedimentation test. Crop Sci. (27): 253-257.

Payne PI, Lawrence GJ (1983). Catalogue of alleles for the complex loci, Glu-A1, Glu- D1 which code for HMW subunits of glutenin hexaploid wheat. Cereal Res. Commun. (11): 29-35.

Payne PI, Nightingale MA, Krattiger AF, Holt LM (1987). The relation between HMW glutenin subunits composition and bread making quality of British grown wheat varieties. J. Sci. Food Agric. (40): 5165.

Randall PG, Manley M, Meiring L, McGill AEJ (1992). The high molecular weight glutenin subunits of South African wheats. J. Cereal Sci. (16): 211-218.

Shewry PR, Halford NG (2002). Cereal seed storage proteins: structures, properties and role in grain utilization. J. Exp. Bot. (53): 947-958.
Tahir ISA, Nakata N, Ali AM, Mustafa HM, Saad ASI, Takata K, Ishikawa N, Abdalla OS (2006). Genotypic and temperature effects on wheat grain yield and quality in a hot-irrigated environment. Plant Breed. (125): 323-330.

Tahir ISA, Nakata N, Ali AM, Saad ASI, Tsuji W (2009). Evaluation of conventional and prolonged-swelling sodium dodecyl sulfate sedimentation tests for the prediction of bread wheat quality under heat stress conditions. Expl. Agric. (45): 165-175.

Wieser H, Kieffer R (2001). Correlations of the amount of gluten protein types to the technological properties of wheat flours determined on a micro-scale. J. Cereal Sci. (34): 19-27.

Zheng S, Byrne PF, Haley SD, Shan X, Reid SD (2010). Glutenin allelic variation and $1 \mathrm{AL} .1 \mathrm{RS}$ effects on dough mixing properties of wheat grown in irrigated and rainfed Eenviron.ments. Euphytica, (176): 357369. 